\title{
Electric heating as flexible demand for enhanced network operation
}

\author{
David Moretti ${ }^{凶}$, Stuart Galloway \\ University of Strathclyde, Glasgow, Scotland \\ $\bowtie$ E-mail: david.moretti@strath.ac.uk
}

\begin{abstract}
Electrical distribution networks are facing a number of network challenges, which combined with the anticipated transition towards a distribution system operator model will place increased emphasis on network and demand flexibility. The use of direct or storage electric heating to facilitate demand side management and/or response services address a number of these emerging distribution network operation and performance challenges, particularly in relation to increasing distributed generation and system support services. The ability to deliver such services rests on the implementation of robust, resilient, prioritised and coordinated control and communication functionalities and capabilities.
\end{abstract}

\section{Introduction}

Electrical heating is an established component of the UK's electrical system demand, control and operation, primarily in the form of existing residential direct or storage electrical heating [1]. The desire to decarbonise the UK's heat energy demand has led to a focus in recent years on electrified heating as a potential solution with heat pumps as the preferred technology replacement for the existing heating systems with associated provision of network services [2]. However, with the ongoing improvements in the operational performance and control capabilities of direct and storage electric heating, this technology has the potential to emerge as a rival candidate for the electric heating and the provision of flexible demand [3].

This paper considers how modern direct or storage electric heating can be used to address a number of the challenges that electricity distribution networks faces by acting as a flexible demand.

In Section 2 an overview of electric heating usage and distribution network is provided, Section 3 focuses on the technology options, Section 4 highlights the network challenges with Section 5 addressing the role of electric heating as flexible demand followed by a discussion in Section 6, conclusions in Section 7 and finally references.

\section{Electric heating and distribution networks in Scotland}

Scotland differs from the majority of the UK, a significant proportion of domestic households $(16 \%)$ are off-gas grid which means that they are unable to use natural gas-fuelled boilers as their primary heat source. This lack of gas infrastructure has contributed to the levels of domestic electric heating in Scotland $(13 \%$ of households) being significantly higher than the UK average ( $9 \%$ of households) [4].

The Scottish Government's Heat Policy Statement [5], while focusing on decarbonising heat, recognises the role that electric heating could play in increasing renewable generation capacity, extending distribution network asset life and providing operational flexibility.

The high levels of distributed generation (DG) currently connected or planned to connect to the electricity distribution networks in Scotland means that they are presently subject to significant planning, operational and performance constraints [6, 7]. Such constraints could be eased by increased levels of network and demand flexibility within the existing demand base, including electric heating.

The anticipated paradigm shift from the current passive distribution network operator (DNO) basis towards the proactive distribution system operator (DSO) is being actively considered nationally [8] and within Scotland [9]. Such a transition provides a forum, incentives and opportunities for existing, replacement or new direct or storage electric heating to provide demand side response (DSR) and associated services at lower installation costs and timescales than the future installation of heat pumps.

A number of projects have been developed and implemented within the Scottish Islands [10-12] to use domestic electric heating to ease network constraints while providing network ancillary and balancing services. Such projects provide a mechanism to establish what is technically and commercially possible while also addressing the social acceptability of alternative heating control and operating regimes and as such are vital in demonstrating effective flexible demand service provision.

The scale of the electric heating demand, combined with the extent of the distribution network issues presented by the substantial level of DG indicates that there can be significant role for modern electric heating technologies in the progress towards decarbonisation of heat [13] and development of the DSO role within Scotland.

\section{Electric heating technologies}

While domestic heat pumps are seen as emerging electric heating technologies that will have an increasing presence and impact on the UK's electrical networks [2], they still face a number of potential economic, behavioural, technical and supply-side barriers $[14,15]$, as summarised in Table 1 . These barriers may contribute in various ways to preclude heat pumps from being the preferred technology choice under a number of circumstances.

Direct or storage electric heating is an established technology which is beginning to receive renewed attention across a range of customer applications (e.g. rural off-gas-grid, urban high-density dwellings) where heat pumps may be not be viable or appropriate [16]. Their technology, controls and communications are such that they have the potential for efficient, flexible and responsive demand services as well as meeting customer heating needs $[10,11]$ It is possible with appropriate aggregation, co-ordination and prioritisation of individual residence heating system controls to deliver both network operational and optimisation benefits in 
Table 1 Potential heat pump deployment barriers [15]

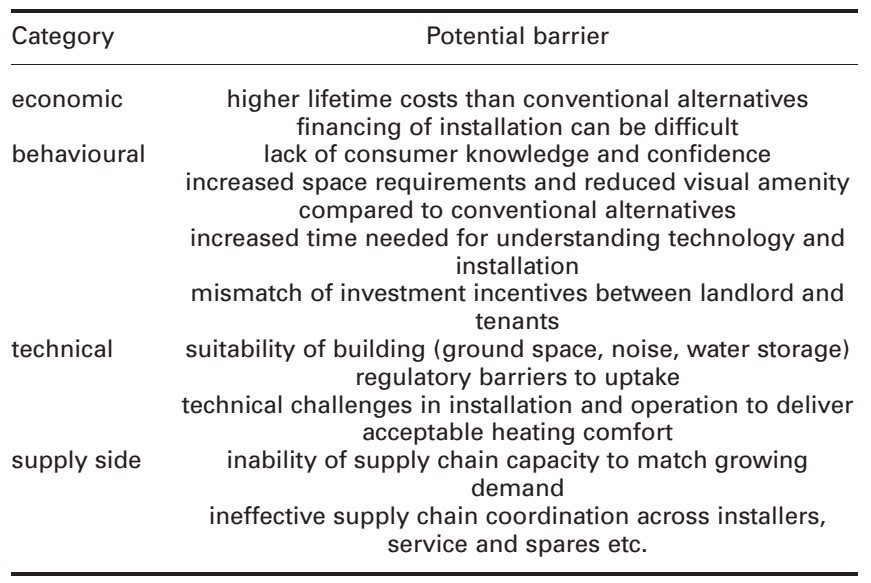

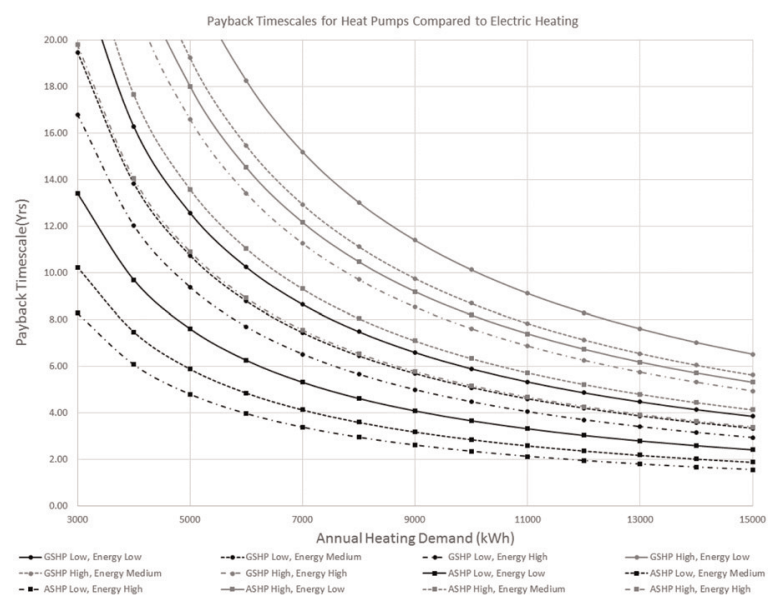

Fig. 1 Payback period for heat pumps compared to electric heating

conjunction with DSR while still maintaining satisfactory customer heating comfort levels [17].

A comparison of the capital [Indicative capital cost range of $£ 7000-£ 11,000$ for air sourced heat pumps (ASHP) and $£ 13,000$ $£ 20,000$ for ground sourced heat pumps (GSHP) [18].) and operational [Taken as $8 \mathrm{p} / \mathrm{kWh}$ (low), $12 \mathrm{p} / \mathrm{kWh}$ (medium), $16 \mathrm{p} / \mathrm{kWh}$ (high).] costs of electric heating with heat pumps and calculation of the payback period for heat pumps, is shown in Fig. 1. This shows that the payback period before heat pumps would begin to represent a viable economic heating system compared to electric heating could be prolonged ( $>10$ years) particularly if the heat pumps capital costs are high, energy costs are low or annual heating demand levels are low.

The potential deployment barriers for heat pumps combined with their possibly 'longer' payback periods suggest that the replacement, refurbishment or new installation, of direct or storage electric heating still present a technically and economically advantageous domestic heating solution for a number of years.

\section{Network challenges}

Electrical distribution networks are facing a number of challenges including the following:

(i) aging asset base with high upgrade/replacement costs,

(ii) divergence of operational basis and performance from intended design basis due to increasing DG penetrations,

(iii) desire for increased levels of network and demand flexibility, (iv) emergence of active network management (ANM) as a short-term or enduring operational and asset management approach, (v) emergence of new, complex, dynamic pricing structures and tariffs.

The main focus of this paper is on (ii), (iii) and (iv) and the role that direct or storage electric heating acting as flexible/responsive network demand would provide.

\subsection{Operational and performance impact of DG}

Ongoing increases in DG are having wide-reaching impacts on both the operation and the performance of the distribution networks. The utilisation of flexible demand which was either directly or indirectly controlled to respond to key aspects of network performance could increase and extend the networks operational capabilities to economically and efficiently accommodate DG.

\subsection{Network and demand flexibility}

There is a growing recognition of the extent, nature and importance that demand flexibility could play in the efficient and economic operation of both the existing and the future network operations [8].

Key areas where network, and by implication, demand flexibility are being sought include the following:

- Post-fault or outage demand response as part of a network operator's operational measures.

- Peak load lopping to avoid asset replacement due to breaching of thermal ratings and/or security of supply criteria. Deferment or avoidance of asset replacement would be expected to lead to cost savings and environmental benefits.

- Off-peak load shaping for optimisation or limitation of key network performance parameters such as equipment thermal loadings, system losses, voltage regulation and profiles, generation unit scheduling and commitment, asset utilisation.

- Provision of existing ancillary support services such as frequency response (primary, secondary and enhanced).

- Increasing need for ancillary and balancing services, currently vested in large/centralised service providers or plants which are likely to move towards an increasingly decentralised provision via DSOs.

\subsection{ANM}

As the transition towards ANM as 'business as usual' continues to gather pace with alternative, managed or flexible generation connections offered by all UK DNOs, the main focus to date has been on the generation abatement or curtailment as the main mechanism of achieving the ANM management objectives [19].

The implications of such generation curtailment for low carbon generation which have no means to preserve or store fuel supplies such, as solar, wind, run of river hydro, is a direct loss of revenue. There is also the additional environmental disadvantage that the constrained low carbon generated energy is likely to be replaced by conventional fossil fuel generation energy.

The capabilities of ANM schemes in achieving their network management objective could be augmented by the introduction at scale of elements of flexible, controllable demand while reducing curtailment of low carbon generation sources.

In this case the challenges faced by the electrical distribution networks can be both exacerbated and ameliorated, by the use of controlled electric heating to provide flexible and controllable network demand.

\section{Electric heating as flexible demand}

The capability of electric heating to operate under direct or indirect control while operating under demand side management (DSM) or as DSR to planned or unplanned network events, are summarised in Table 2 . 
Table 2 Flexible demand capabilities

\begin{tabular}{|c|c|c|c|c|c|c|}
\hline \multirow[t]{3}{*}{ Flexible demand service } & \multicolumn{2}{|c|}{ DSM } & \multicolumn{4}{|c|}{ DSR } \\
\hline & \multirow[b]{2}{*}{ Direct control } & \multirow[b]{2}{*}{ Indirect control } & \multicolumn{2}{|l|}{ Planned } & \multicolumn{2}{|c|}{ Unplanned } \\
\hline & & & Direct control & Indirect control & Direct control & Indirect control \\
\hline voltage controlled & high potential & high potential & high potential & high potential & high potential & high potential \\
\hline peak lopping & high potential & high potential & high potential & high potential & N/A & N/A \\
\hline load shaping & high potential & high potential & high potential & high potential & N/A & N/A \\
\hline post-fault response & $\mathrm{N} / \mathrm{A}$ & N/A & $\mathrm{N} / \mathrm{A}$ & N/A & high potential & limited potential \\
\hline frequency response & $\mathrm{N} / \mathrm{A}$ & N/A & N/A & N/A & high potential & limited potential \\
\hline short-term operating reserve & N/A & N/A & N/A & N/A & high potential & limited potential \\
\hline $\begin{array}{l}\text { DG curtailment reduction } \\
\text { dynamic tariff }\end{array}$ & $\begin{array}{l}\text { high potential } \\
\text { N/A }\end{array}$ & $\begin{array}{l}\text { limited potential } \\
\text { high potential }\end{array}$ & high potential & $\begin{array}{l}\text { limited potential } \\
\text { high potential }\end{array}$ & $\begin{array}{l}\text { high potential } \\
\text { N/A }\end{array}$ & limited potential \\
\hline
\end{tabular}

The use of direct or storage electric heating to provide the capabilities in Table 2 have a number of potential advantages over the use of heat pumps:

- The extent of the flexible demand per installation would be greater due to the increased demand levels of direct or storage electric heating.

- If demand flexibility can be provided at individual room heater level the degree of controllability can be extended while maintaining consumer comfort.

The use of storage in the form of either energy or thermal storage or a combination of both can extend both the scope and range of flexible demand services offered [16]. Typically, this would increase the control complexity but it may increasingly form part of the capabilities offered by the expanding number of domestic energy and environmental control systems.

While a number of the demand flexibility services can be complementary, there is the potential for conflict between the services and their responses characteristics with the need for a hierarchy, prioritisation, optimisation and coordination of services and characteristics [20]. One option would be for an aggregator to deliver the demand flexibility capabilities but they may not be able to provide all functions within the required network event response times. There is therefore the need for a combined control approach between the aggregator and the DSO, with the DSO having some form of direct control capabilities to support time-critical network operational demand response.

The means by which the various control responses would be implemented and regulated also needs to be considered. In some cases these may be set (e.g. voltage/frequency response) and broadcast regularly, while in others more direct action with associated control and communications requirements (e.g. load matching) may be required. If electric heating is to provide flexible demand then reliable, secure, resilient communications are essential, with appropriate interfaces with external parties (i.e. aggregators, ANM, DSO management system) [21]. The nature and type of the communication and control infrastructure may be dependent on the services offered and would need to control not just positive actions (e.g. load reduction or increase), but also regulate/mitigate the impact of negative actions (e.g. electric heating all switching on simultaneously) following reduction, to avoid any adverse network interactions/impacts [22].

The provision of secure, reliable, timely communications will present installation, operational and economic challenges with the need for careful consideration as how they must be provided, since poor or slow communications are likely to restrict the flexible demand services that are offered [21].

The extension of an ANM scheme is to include generation, demand and, if available storage would increase the potential range and extent of network management activities with a move from a reactive network management approach towards a more proactive approach. For example, if a network has ANM managed constrained wind or PV-based DG, inclusion of electric heating-based flexible demand could allow the ANM controller to
Table 3 Key characteristics of urban and rural networks

\begin{tabular}{lcc}
\hline Characteristic & Urban & Rural \\
\hline $\begin{array}{l}\text { load density } \\
\text { circuit distances } \\
\text { dominant circuit } \\
\text { construction }\end{array}$ & high & low \\
typical DG density & short & long \\
DG types & cable & overhead line \\
key network issues & lower & higher \\
& PV, CHP, EfW & wind, PV, hydro \\
& thermal, & thermal, voltage, \\
voltage & constraints
\end{tabular}

determine and schedule electric heating load profiles to minimise generation constraints. Information used would typically include weather forecasts, estimated generation output and demand levels based on load profiles and characteristics. The use of ANM for DSM has been demonstrated as part of the Low Carbon London project [23].

\section{Discussion}

Electric heating-based flexible demand can take differing roles within different network topologies, such as urban and rural networks, the key characteristics of which are given in Table 3.

Within urban networks, it may be network demand-based thermal loading issues which dominate, therefore peak lopping or load shaping may be the desired flexible demand response. Alternatively, with increasing levels of urban PV generation and potential to increases in other forms of urban DG [e.g. energy from waste (EfW), combined heat and power (CHP)] then other flexible demand services such as constraint relaxation or the introduction of virtual private wire (VPW) to facilitate trading, with time can become desirable features of urban networks.

In a rural network context, the prime advantage of electric heating as flexible demand would tend to be realised in the aspects associated with DG-based network effects, primarily easing of voltage and thermal constraints. However peak lopping or load shaping flexible demand capabilities could also be beneficial, especially if expensive or contentious network reinforcements or upgrades were considered.

The retrofitting or replacement of existing electric heating systems with modern heating systems would be expected to be accommodated within distribution networks with no or minimal network upgrades since the network capacity and infrastructure is already in place.

\section{Conclusions}

The use of DSM and/or DSR services offers solutions to a number of distribution network operation and performance challenges, particularly in relation to increasing DG levels and system support service requirements. 
The retrofitting or replacement of existing electric heating with modern direct or storage heating systems and/or control and communications could introduce significant levels of flexible demand into distribution networks within existing asset bases while providing increased consumer heating comfort and reduced energy costs.

The use of direct or storage electric heating-based flexible demand may provide a suitable platform for DSO and wider network flexibility services from which future approaches for the wide scale deployment of heat pumps or increases from existing direct or storage electric heating levels could be supported.

A critical factor in the ability to deliver such services would rest on the implementation of robust, resilient, prioritised and coordinated control and communication functionalities and capabilities which would need to take into account both direct and indirect control regimes with potential conflicting or competing objectives from multiple service providers and/or users.

\section{Acknowledgment}

This work has been supported through the EPSRC Centre for Doctoral Training in Future Power Networks and Smart Grids (EP/ L015471/1)

\section{References}

1 Department of Energy \& Climate Change: 'United Kingdom housing energy fact file' (Department of Energy \& Climate Change, London, 2013)

2 National Grid: 'Future energy scenarios' (National Grid, London, 2016)

3 DNV KEMA Energy \& Sustainability: 'Potential for smart electric thermal storage: contributing to a low carbon energy system' (KEMA Nederland, Arnhem, 2013)

4 The Scottish Government: 'Energy in Scotland 2016' (The Scottish Government, 2016)

5 The Scottish Government: 'Heat policy statement: towards decarbonising heat: maximising the opportunities for Scotland' (The Scottish Government, Edinburgh, 2015)

6 Scottish Power Energy Networks: 'Distributed generation heat map application'. Available at http://www.spenergynetworks.co.uk/pages/sp_distribution_heat_ maps.asp, accessed 10 November 2016
7 Scottish \& Southern Electricity Networks: 'Generation availability map'. Available at https://www.ssepd.co.uk/GenerationAvailabilityMap/?mapareaid=2, accessed 10 November 2016

8 Institution of Engineering and Technology: 'The future power system architecture project'. Available at http://www.theiet.org/sectors/energy/resources/fpsa-project. cfm? origin=reportdocs, accessed 20 December 2016

9 SP Energy Networks: 'DSO vision consultation'. Available at http://www. spenergynetworks.co.uk/pages/dso_vision_consultation.asp, accessed 10 November 2016

10 Scottish \& Southern Electricity Networks: 'Northern Isles new energy solutions (NINES)'. Available at http://www.ninessmartgrid.co.uk/, accessed 10 November 2016

11 ACCESS: 'Assisting communities to connect to electric sustainable sources'. Available at http://www.accessproject.org.uk/, accessed 10 November 2016

12 Rousay Eglisay \& Wyre Development Trust: 'Heat smart Orkney'. Available at http://www.rewdt.org/index.php?link=hsoAbout\&name=HSO, accessed 10 November 2016

13 Scottish and Southern Energy: 'Proposals for Scotland's energy future'. Available at $\mathrm{http} / / /$ sse.com/newsandviews/allarticles/2016/12/proposalsforscotlandsenergy future/, accessed 16 December 2016

14 Akmal, M., Fox, B., Morrow, J.D., et al.: 'Impact of heat pump load on distribution networks', IET. Gener. Transm. Distrib., 2014, 8, (12), pp. 2065-2073

15 Frontier Economics and Element Energy: 'Pathways to high penetration of heat pumps: report prepared for the committee on climate change' (Frontier Economics Ltd, London, 2013)

16 Ward, J., Darby, S.: 'The household electricity demand-side \& participation in the GB electricity markets', Sustainability First, 2014

17 Darby, S.J.: 'Balancing the system comfortably? Electric storage heating and residential demand response'. 4th European Conf. Behaviour Energy Efficiency, Coimbra, 2016

18 Energy Savings Trust: 'Renewable heat'. Available at http://www. energysavingtrust.org.uk/renewable-energy/heat, accessed 16 December 2016

19 ENA: 'Active network management good practice guide' (Electricity Network Association, London, 2015)

20 Clarke, J., Hand, J., Kim, J., et al.: 'Performance of actively controlled domestic heat storage devices in a smart grid', Proc. IMechE Part A: J. Power Energy, 2015, 229, (1), pp. 99-110

21 Mets, K., Ojea, J.A., Develder, C., et al.: 'Combining power and communication network simulation for cost-effective smart grid analysis', IEEE Commun. Surv Tutor., 2014, 16, (3), pp. 1771-1796

22 Tindemans, S.H., Trovato, V., Strbac, G., et al.: 'Decentralised control of thermostatic loads for flexible demand response', IEEE Trans. Control Syst. Technol., 2015, 23, (5), pp. 1685-1700

23 Gault, C., Olmas Mata, D., Sokari-Briggs, T, et al. 'Experiences from an active network management trial on an urban network'. CIRED Workshop, Rome, 1112 June 2014 